\title{
A Review of Rice Landraces in India and its Inherent Medicinal Values -The Nutritive Food Values for Future
}

\section{A. Mohammed Ashraf ${ }^{1 *}$ and Subbalakshmi Lokanadan ${ }^{2}$}

${ }^{1}$ Department of Agronomy, Agricultural College and Research Institute, Madurai - 625104, Tamil Nadu, India

${ }^{2}$ Department of Agronomy, Tamil Nadu Agricultural University, Coimbatore - 641003, Tamil Nadu, India

*Corresponding author

\section{A B S T R A C T}

Rice being staple food has additional qualities beyond its nutritive value with high degree of digestibility and least allergic properties compared to other cereal grains (Leena kumary, 2004). Traditional rice landraces in India and across Asia are under serious threat of extinction due to cultivation of modern and high yielding varieties (HYVs), hybrids and genetically engineered rice (Yogesh, 2011). The red rice varieties with appealing red

Keywords

Medicinal values, Nutritive values, Rice landraces.

Article Info

Accepted:

04 October 2017

Available Online:

10 December 2017 colour, has more complex taste and contains more nutrition, fibre-filled bran compared to normal rice. In the red rice, colour is confined to the bran layer, ranging from light red to dark red, a tinge of red remains even after a high degree of milling and contains polyphenols, anthocyanin and possess antioxidant properties. The inner portion of red and the normal white rice consumed is alike and white. The zinc and iron content of red rice is two to three times higher than that of white rice (Ramaiah and Rao, 1953). Rice is considered as food with high carbohydrate and some amount of protein, but has a number of unknown properties, as reported in ancient Indian Ayurvedic literature, where apart from consumption, the scientific literatures like 'SusruthaSamhitha' and 'CharakaSamhitha'- 1000 $\mathrm{BC}$ had given evidences of few rice varieties that had the "medicinal properties" and were used for treating human ailments since long time in our country, certain rice landraces are still popular even now among farming community. The rice landraces, due to their adaptability to different agro climatic conditions, unique characteristics and special use are confined to only certain rice growing areas in particular season. The recent studies also recommend rice as a novel food due to its high glycemic index for lowering the incidence of certain lifestyle - related diseases such as heart attack, diabetes and cancer (Rhodes, 2008).

\section{Introduction}

Traditional rice varieties in India and across Asia are under serious threat of extinction due to arrival of modern rice varieties, high yielding varieties (HYVs), hybrids, and genetically engineered rice being developed as an outcome from partnership corporatecentered technology.
Over the last decade, the genetic instability of the acquired traits in modern rice varieties and the associated environmental degradation have caused a continuous decline in yields and quality of food grains in several Asian countries. This has caused great anxiety to the planners and administrators aiming to meet 
the food requirements of their burgeoning population.

India is presently facing a rice/ food crisis mainly due to the erosion of its biodiversity and increase of monocropping in agriculture. Trade liberalization policies have intensified, industrial agriculture and cash cropping are in the country's race for comparative advantage in global trade - intensifying the ravages of overuse of chemicals, declining soil fertility and resources such as water. As climate change in the environment has lead to frequent floods and prolonged droughts, the order of the day in India, is the modern high yielding rice varieties and hybrids suffer most, leading to partial or total loss of crops.

\section{Biodiversity of traditional rice varieties in India}

Well-known Indian rice researchers, Richharia and Govindasamy (1990), have reported in their book 'Rice of India' which provides Vedic and present day literature evidence to show that the country had been endowed with more than 2 lakh $(200,000)$ rice varieties, a rich biodiversity that no other country on earth possesses. Each and every variety of rice is the result of the vision and hard work of women and men of past generations who toiled to select rice varieties which are adapted to different climate, soil types, topography and agronomic practices. In the Chattisgarh region of Maharashtra alone, Dr. Richharia identified more than 20,000 rice varieties.

However, this rich rice biodiversity has been steadily declining in phases due to the scientific advancement created in the field of plant breeding and genetics, and Deb (2005) in his famous book entitled "Seeds of Tradition, Seeds of Future" provided detailed morphological descriptions of 416 Indian traditional rice varieties, which are on the verge of extinction from farmers' fields. Cowell (1957), Kangle (1966), Keith (1967), Cleveland et al., (1993, 2000), Arumugasamy et al., (2006) and Sathya et al., (2007) reported large number of traditional rice varieties found in different parts of India and their adaptation to certain specific conditions.

The replacement of traditional rice varieties by modern rice varieties

The major reason for the disappearance of thousands of local rice varieties is their steady replacement with the high-yielding varieties (HYVs) introduced in 1960's coinciding with Green Revolution (GR). Farmers were impressed by the initial high yields of these so-called 'miracle' seeds and ignored the associated costs of external inputs, subsequent loss of non-grain bio-mass, loss of desirable traits (like tolerance to diseases and pests, drought, floods, etc.), and the extensive deterioration of the environment, including soil and water.

Despite the apparent failure of the long term sustainability and viability of the GR technological fixes and growing threats of the Gene Revolution (using genetic engineering), these so-called 'scientific' and 'modern' varieties continue to be aggressively promoted at the expense and exclusion of traditional varieties. For example, the success of HYVs in wetland farms has often prompted state agricultural scientists and extension staff to promote these crops by exaggerating their yields, claiming to be higher than those of indigenous varieties. But this was not true for many varieties. During the 1960's the high yield recorded in 1R-8 and ADT 27 in the Cauvery Delta farms in Tamil Nadu were advertised as a triumph of HYVs over the 'low yield' of indigenous varieties like Kuthiraivali, Kurangu samba, Kitchili samba, etc. While these HYVs did produce higher yields initially, they stagnated and finally 
from the disappeared from the rice cultivation scenario after some years. The traditional varieties mentioned above are still under cultivation by large number of farmers in different areas. The comparatively getting higher yields by large number of these landraces (plants adapted to the natural and cultural environment of their origin) on rainfed land and seasonal inundated farms have remained systematically downplayed in most agriculture development programmes.

As a consequence of the green revolution (GR) many common rice landraces like Dharical, Dular and TilakKacheri, which were remarkably adapted to different soils, climates and topological conditions in the state, are now at extinction in eastern India (Richharia and Govindasamy, 1990). Arumugasamy et al., (2007) narrated that in Tamil Nadu, a large number of farmers preferred to cultivate traditional variety rice called Kappakar in the clayey soils of Madurai rather than HYVs owing to the fact that Kappakar is tolerant to drought, flood, pest and diseases. For decades, farmers of Trichy District have cultivated a traditional variety called Samba Mosanam in the illdrained soils of Arasankudi Village while the HYVs had succumbed.

\section{Traditional rice varieties in India}

The World Wildlife Fund (WWF) - India survey, conducted in 1994 in six districts of southern West Bengal, recorded 137 traditional rice varieties, still surviving in the marginal farms of rice growers. There are many varieties which are drought tolerant, flood-tolerant and amenable to ill-drained and lowland cultivation. A large number of varieties possess the characteristics of disease and pest-resistance. Some of them have the unique characteristics of tolerance to salinity, alkalinity and being able to grow in 'deepwater' inland areas. The most significant characteristics that some of the traditional varieties possess is their medicinal and nutritional traits and the fact is that the consumers prefer them (Deb, 1995).

\section{The yield of traditional rice varieties}

Compared to other cereals including wheat, rice is a high yielding crop, even under adverse conditions. When the water supply is adequate, and naturally occurring nitrogen fixing organisms exist in the paddy fields, no synthetic fertilizers are required to produce upto $2 \mathrm{t} \mathrm{ha}^{-1}$ of the local variety of rice. Characteristics that determine the yield potential of rice cultivars are the number of "productive" tillers per hill and panicle density (number of grains per panicle and grain weight). Many native varieties have greater mean panicle density and grain weight than most HYVs. Varieties like Ashphal, Bakulphool, Bokva, Ganga sal, Patnai, etc. have heavy grains. The mean panicle weight of several landraces processed by the rice farmers like Ashphal, Bahurupi, BanshPata, Banshtara, Juqal, Kabiraj-sal, Keralasundari, Lukkhan-sal, Panjab-sal, etc. are more than $5 \mathrm{~g}$ (Swaminathan, 1984).

The yield in rice crop is calculated as production of grains per unit of inputs of water and agrochemicals. In respect to these aspects most of the local landraces have better yield than any HYVs reported by Cleveland et al., (1993) and Deb (1995, 2000). In particular, rice grain yields may be objectively measured in terms of output per unit of nitrogen fertilizer input. By these analyses, the yields of most local rice landraces seem to be spectacularly higher when compared to HYVs. Even in absolute terms of grain output per unit area of farm, a number of native rice varieties have considerably high yields of grains on farms located in highly stressful environments. It is well known that modern crop varieties often 
fail to perform well in challenging environments.

In fact, Cleveland et al., (2000) noted that local landraces grown on farms with zero agrochemical inputs produced rice quantity that often outperformed most HYVs in terms of grain output over a wide range of environmental conditions. In their research on the traditional rice varieties of Tamil Nadu, Sathya et al., (2007) revealed some significant findings on the ability of native varieties to withstand many conditions as well as display other important traits. Karunguruvai has been found to have the property of curing Filariasis (commonly called "elephant's foot"), a disease spread by mosquitoes. A lehyam (paste) is prepared by boiling Karunguruvai rice with cactus milk, cow's milk and honey. If the lehyemis consumed by those suffering from the disease for a period of ten days, it is reported that this will cure them or keep the disease under control. Kappakar rice variety is grown in dry land areas and can survive and produce yields even under extreme dry conditions where no other rice cultivars can survive. Hence Kappakar can be grown by dry land and rainfed farmers even in small areas for their food security (Arumugasamy et al., 2007).

Under lowland or ill-drained conditions where most HYVs and local landraces succumb to water logging, it is the traditional rice variety Samba Mosanam alone that is best known to survive such conditions and produce high yields. It is also suitable for cultivation in lakes (on the periphery) during non-rainy seasons, when there is no water in some areas. When water fills the lakes during the rainy season, these paddy landrace plants also grow in height; commensurate with the rising waters. It is said that people travel in boats and harvested the panicles of Samba Mosanam in lakes (Arumugasamy et al., 2006).

\section{Red rice}

Rice with a red bran layer is called red rice. Though the colour is confined to the bran layer, a tingle of red remains even after a high degree of milling. The colour of the bran ranges from light to dark red. The bran layer contains polyphenols and anthocyanin, and possesses antioxidant properties. The inner portion of red and white rice is white alike. The zinc and iron content of red rice is twothree times higher than that of white rice (Ramaiah and Rao, 1953). American scientists have reported similar high iron content in the Chinese red varieties Bloody Sticky and Dragon Eyeball (Rood, 2000).

The change in food habits from traditional foods to junk foods has increased the risk of lifestyle-related health issues and diseases such as diabetes, cancer and heart problems. Red rice meets most of the requirements of a good and healthy food. This cereal is the only one that is eaten consumed as a whole grain, and is more easily digestible. As red rice has been found to have greater antioxidant property than white rice, it underlines the swift need to reinstate them into daily diets of people (www.agrariancrisis.in /2012).

The annual acreage of different coloured rice in China is 1.26 per cent of the total rice cropping area (Chaudhary and Tran, 2001). In Bhutan, about 30 per cent of the area is under red rice. In an evaluation programme for biotic stresses, with around 12,750 rice entries have been reported by Indian Institute of Rice Research, Hyderabad, India, 28.31 per cent of entries were coloured rice. Of these 10.48 per cent, 9.41 per cent and 8.40 per cent were red, brown, and purple pericarps. The collection from Central Rice Research Institute, Cuttack, Orissa with 2,960 entries, mainly from the eastern states of India, had a relatively high number of red rice of which 20 per cent were coloured rice. Of which, 17.40 per cent, 3.44 
per cent, and 2.50 per cent were red, purple and brown rice respectively. A survey conducted by the National Bureau of Plant Genetic Resources, NBPGR from 1991 to 1998 recorded about 35 per cent and 21 per cent of rice as traditional red rice varieties in Orissa and Manipur (Krishnamurthy and Sharma, 1970; Dikshit et al., 2004). This coloured riceis rich in minerals like iron, zinc and polyphenol content with antioxidant properties. So, these landraces are gaining interest for research studies. In Tamil Nadu, more number of red rice land races continues to exist in Ramnad District and they are found to be drought resistant.

The average yield of many traditional rice varieties was found to be in the range of 1.7 to $2.5 \mathrm{t} \mathrm{ha}^{-1}$ and has the chance to explore the possibilities of enhancing yield under irrigated ecosystem while in Ramnad district red rice landraces are raised under rainfed situation leading to less yield.

A number of red-grained varieties were cultivated in Kerala, Tamilnadu, Karnataka, Bihar, Orissa, Bengal, Madhya Pradesh, and northeastern states with areas having unfavorable conditions such as deep water, drought, sandy soils, salinity and cold conditions.

\section{Rice and ayurveda}

Medicinalrice varieties are used extensively in the ayurvedic system of medicine. According to Susrutha, rice can be broadly classified into two kinds, Saali rice and Vreehi rice. Saali rice is characterized by a red husk and white kernel and is mostly grown during the winter season. Vreehi rice has different husk colours, with red kernels and is grown during the rainy season. Saali rice is considered Laghu, meaning light or easily digestible, is cooling and diuretic, alleviates thrist, and reduces Vatha, Pitha and Kapha. Among the Saali rice varieties, the most important and the best one is RakthaSaali, so called for its pigmented plant parts and red-husked grains. Among the Vreehi varieties, Shastikam, which matures in a short period of 60 days (Leena Kumary, 2004).

\section{Medicinal rice heritage of Kerala}

Some of the traditional varieties that were in cultivation in Kerala in olden days (Chennellu, Kunjinellu, Chembavu, Kalamappari, Neduvali, Velvali, etc.).Chennellu is considered as the best and least harmful. AnduvilaChennellu, another Saali variety taking one year to mature was considered to increase Kapha and Pitha and hence not recommended for daily use. Varieties such as Njavara, Perunellu, Valanellu, Chitteni, Modanetc. were some of the important Vreehi varieties that were found in Kerala (Nair, 2004).Kerala is blessed with a number of rice varieties with medicinal and curative properties. Some of these medicinal rice is present only in literature and is not in cultivation any more. However, some varieties are still being cultivated in restricted pockets of Kerala on a small scale for their medicinal properties e.g. Njavara, Chennellu, Kunjinellu, Erumakkari and Karuthachembavu (Elsy et al., 1992; Menon and Potty, 1999).

\section{Njavara, the magic spell from Kerala}

Njavararice is of two types viz., whitish and blackish. Shastikam is a Njavara variety which takes 60 days for harvest. Ashtangahridayam indicates that the white one is superior to the black one but many practicing physicians use black glumed Njavara, the white (yellow) variety is popular in the southern districts of Kerala, whereas in northern districts, the naturopathy practitioners use the black variety (Nair, 2004; Leena Kumary, 2004). 


\section{Studies on Njavara}

Elsy et al., (1992) found high variability noticed among Njavara genotypes with respect to lemma and paleacolour. Two major classes based in glume colour variability could be distinguished as yellow (straw colour) and black Njavara types. Grain of seven genotypes viz., $\mathrm{N}_{2}, \mathrm{~N}_{6}, \mathrm{~N}_{11}, \mathrm{~N}_{12}, \mathrm{~N}_{13}$, $\mathrm{N}_{14}$, and $\mathrm{N}_{15}$ exhibited black colour of lemma and palea. Black furrow on straw background was noticed in $\mathrm{N}_{1}$. The genotypes $\mathrm{N}_{3}, \mathrm{~N}_{5}, \mathrm{~N}_{8}$ and $\mathrm{N}_{10}$ exhibited a lemma and palea colour of gold furrow on straw background. Brown furrow on straw background was noticed in $\mathrm{N}_{4}, \mathrm{~N}_{7}, \mathrm{~N}_{9}$.Apart from the above characters, 1000 seed weight of the genotypes were also recorded. It ranged between $17.52 \mathrm{~g}$ to 22.70 $\mathrm{g}$. The maximum seed weight was shown by the genotype $\mathrm{N}_{10}$. L/B ratio also worked out for grain classification. Accordingly they were classified as medium and bold. Genotypes $\mathrm{N}_{1}, \mathrm{~N}_{2}, \mathrm{~N}_{3}, \mathrm{~N}_{4}, \mathrm{~N}_{5}, \mathrm{~N}_{6}, \mathrm{~N}_{7}, \mathrm{~N}_{8}, \mathrm{~N}_{9}$, $\mathrm{N}_{10}, \mathrm{~N}_{11}, \mathrm{~N}_{12}, \mathrm{~N}_{13}$ and $\mathrm{N}_{14}$ were grouped as bold type (L/B ratio of 2.0 or less than 2.0) and $\mathrm{N}_{15}$ as medium type (L/B ratio of 2.1 3.0) according to the International System for Rice grain classification (ISR).

\section{Therapeutic value of Njavara}

Ashtangahridayam advocated the inclusion of Njavara rice in the diet during the time of Pathyacharana (observing a strict time schedule and following special rules normally after undergoing ayurvedic treatments, especially Panchakarma). The oil prepared out of Njavara rice is used for a wide range of aches and pains such as cervical spondylosis, lower back ache, paralysis and rheumatoid arthritis. Njavara finds use in Njavarakizhi, which is mainly Njavara based. The specialty treatment from Kerala based on the preparatory procedure of Panchakarma therapy. It is practiced in neuromuscular disorders such as hemiplegia, paraplegia, muscular dystrophy etc. Oleation to head and body using special cloth pieces containing a smooth paste of Njavara rice cooked in Sida (Sida rectusa. Lin.) decoction and milk makes the body supple, removes stiffness of joints, cleans the body channels and brings about better blood circulation (Nair et al., 2004).

Hence the rice land races being more nutritious also has varied medicinal properties and in utilized in only localized pockets and areas among the rice growing farmers. So the nutritional value of traditional rice varieties with its inherent medicinal values has poor documentation and hence should be encouraged and supported.

\section{References}

Arumugasamy, S., K. Subramaniyan, S. Subashini and K. Vijayalakshmi. 2006. Traditional rice varieties. Centre for Indian Knowledge Systems. Chennai.

Arumugasamy, S., K. Subramaniyan, S. Subashini and K. Vijayalakshmi. 2007. Traditional rice varieties. Centre for Indian Knowledge Systems. Chennai.

Chaudhary., R.C. and D.V. Tran, 2001. Speciality rice of the world - a prologue. In: Speciality Rices of the World: Breeding, Production, and Marketing (Chaudhary, R.C. and D.V. Tran, eds.). FAO, Rome, Italy; and Oxford IBH Publishers, India. 3-14 pp.

Cleveland, D. A., D. Soleri and S. E. Smith, 2000. A biological framework for understanding farmers' plant breeding. Economic Botany., 54(3): 377-394.

Cleveland, D. A., D. Soleri, and S. E. Smith, 1993. Do folk crop varieties have a role in sustainable agriculture. Bioscience., 44: 740- 751.

Cowell, E. B. 1957.The Jatakas London. Referred in Tuk-Tuk Kumar. 1985. History of rice in India: Mythology, culture and agriculture. Gyan Publishing 
House. New Delhi.

Deb, D. 1995. Sustainable agriculture and folk rice varieties: ecological, economic and cultural aspects. Mimeo. WWF India Eastern Region. Calcutta.

Deb, D. 2000. Folk rice varieties of West Bengal; agronomic and morphological characteristics. Research Foundation for Science, Technology and Ecology (RFSTE/ Vrihi), New Delhi.

Dikshit, N.D., S.S. Malik and J.B. Tomar. 2004. Evaluation studies on genetic resources of rice. Agro Biodiversity38.National Bureau of Plant Genetic Resources (NBPGR) Base Center, Cuttack, Orissa, India.153 pp.

DRR, 2013.Directorate of Rice Research, Annual Progress Report. Rajendranagar, Hyderabad, India. 3: 5.47.

Elsy, C. R., C.A. Rosamma and N.N. Potty. 1992. Njavara - a rice variety with special characters. Oryza. 29: 55-56.

http://agrariancrisis.in/2012/03/19/red-rice-keeps -you-away-from-obesity-diabetes-andcancer/.

Kangle, R. P. 1966. The Kautilya Arthasastra (3 parts). Bombay. Referred in Tuk-Tuk Kumar. 1985. History of rice in India: Mythology, culture and agriculture. Gyan Publishing House. New Delhi.

Keith, A. B. 1967. Veda of the black yajus school, Tailtisiya Samhita.

Krishnamurthy, A. and A.C. Sharma. 1970. Manipur - rich in rice germplasm. Oryza., 7:45-50.

Leena Kumary, S. 2004. Genetic diversity, characterisation and evaluation of medicinal rice in Kerala. In:
Compendium of papers of science society interface on medicinal and aromatic Rice, 20-21 March 2004, held at Regional Agricultural Station, Pattambi, Palakkad, India.

Menon, M.V and N.N. Potty. 1999. Nutritional specificity and quality properties of medicinal rice "Njavara". Oryza, 36(4): 315-317.

Nair, M.C. 2004. Comparative biochemical characterization of indigenous medicinal rice Njavara and selected cultivars of Oryza Sativa L. Project report submitted to Kerala State Council for Science, Technology and Environment.

Ramaiah, K. and M.V.B.N. Rao. 1953. Rice breeding and genetics. ICAR Science Monograph 19.Indian Council of Agricultural Research, New Delhi, India.

Rhodes, A. 2008.Basmati rice- the quality grain. (www.allcreatures.org).

Richharia, R., and S. Govindasamy. 1990. Rices of India. Academy of Development Science. Karjat.

Sathya, A., V. Rajamanickam and K. Ramasamy. 2007. Evaluation of biodiversity in traditional paddy varieties of Tamil Nadu. Ph.D Thesis, Tamil University. Thanjavur. Tamil Nadu.

Yogesh, M. 2011. Studies on organic and inorganic nutrients in SRI for aromatic rice varieties. M.Sc. (Ag). Thesis, TNAU, Coimbatore, India.

\section{How to cite this article:}

Mohammed Ashraf, A. and Subbalakshmi Lokanadan. 2017. A Review of Rice Landraces in India and its Inherent Medicinal Values - The Nutritive Food Values for Future. Int.J.Curr.Microbiol.App.Sci. 6(12): 348-354. doi: https://doi.org/10.20546/ijcmas.2017.612.042 